\title{
Sentence perception units and levels of syntactic structure
}

\author{
JOHN M. CARROLL \\ IBM Thomas J. Watson Research Center, Yorktown Heights, New York 10598
}

\begin{abstract}
Subjects listened to recorded sentences which were followed by probe words. They performed a next-word naming task-uttering the word that followed the probe word in the original sentence as quickly as possible. Other things being equal, naming latencies are longer when the juncture between the probe word and the response word in the original sentence sequence terminates a "functionally complete" unit than when this position corresponds to the boundary of a "functionally incomplete" unit. These results are not predicted by existent "syntactic" theories of sentence perception units, and these theories are to that extent shown to be inadequate. A "functional" program for the study of sentence perception is suggested.
\end{abstract}

One of the central concerns of psycholinguistic research is to specify how listeners process temporally extended speech events, like sentences. One approach to this question is to ask what perceptual units listeners employ when they understand lengthy segments of speech. Much work along these lines during the past 15 years has assumed that some level of syntactic structure defines these units. A great deal of research and some very lively debate has focused on the question of which syntactic level is the relevant level. On the one hand, there is considerable evidence that the major constituents of syntactic surface structures (noun phrases and verb phrases) are treated as perceptual units in sentence perception. On the other hand, however, there is evidence suggesting that the clause, in particular the deep structure clause, is the pertinent syntactic unit.

Several relevant studies have used the "click location" technique. Fodor and Bever (1965) reported that brief bursts of noise superimposed on recorded sentences tended to be subjectively mislocated into surface constituent boundaries. They suggested that interrupting stimuli are deflected into constituent breaks because surface structure constituents are perceptually integral units in sentence perception. Bever, Lackner, and Kirk (1969) reanalyzed Fodor and Bever's data and found that only constituent boundaries corresponding to linguistic deep structure clause boundaries attracted clicks. In two further studies, they demonstrated that clicks were attracted to deep clause boundaries that did not correspond to surface constituent boundaries. They claimed that the deep structure clause was the primary unit in sentence perception.

This research was supported, in part, by NSF-BNS 76-04334. I am grateful to John D. Gould for comments on an earlier version of this paper. Requests for reprints should be directed to J.M. Carroll, 12-136, IBM Watson Research Center, P.O. Box 218, Yorktown Heights, New York 10598.
Chapin, Smith, and Abrahamson (1972) challenged Bever et al.'s conclusions. They showed that, at least for certain constructions, surface constituent boundaries were more likely to attract click mislocations than were deep clause boundaries. Fodor, Bever, and Garrett (1974) reject this challenge, arguing that Chapin et al. used materials whose linguistic analysis is unclear, and thus that no conclusions could be drawn. Somewhat ironically, Kemper, Catlin, and Bowers (1977) have recently brought this same criticism against the original Bever et al. studies. In sum, the identity of these sentence perception units remains elusive.

It is important to note that the fundamental motivation offered for the construct of sentence perception "units" is functional-typically involving an appeal to the limitations of human processing capacity. However, the investigations just reviewed attempt to describe sentence perception units in purely structural terms. These "syntactic" theories of sentence perception rest on the plausible assumption that listeners use their knowledge about sentence structure when they perceptually organize linguistic events. However, these theories have adopted a very rigid posture in applying this assumption. Ignoring "functional" variables leads them to make some rather implausible predictions about sentence perception.

Consider first the view that surface constituents are sentence perception units. The "constituent" view is surely embarrassed by the possibility of sentences like (1):

(1) The big old worn and splintering heavy wooden carriage wheel with the rusted spokes is cracked.

The italicized initial sequence in this sentence is 14 words long, well exceeding most estimates of shortterm processing capacity for unorganized word lists (e.g., Miller, 1956). Nevertheless, the constituent 
view would claim that the listener organizes these 14 words into a unit in order to avoid over-taxing processing capacity. The converse case is illustrated by Sentence 2:

(2) Fleeing was Harry's remedy for his big mouth and vexing personality.

Here, the single word fleeing, surely an unlikely instigator of processing overload, would be organized as a separate unit, because it is a surface noun phrase constituent.

Now consider the view that deep structure clauses are sentence perception units. The "clausal" view would also assert that the single word fleeing is treated as a processing unit, because it corresponds to the deep structure clause Harry flees (see Chomsky, 1970). The clausal view further predicts that the two words the plump in Sentence 3 would be organized as a unit.

(3) The plump girl won the citizenship award.

The reason for this is that the single word plump corresponds to a deep structure clause (see Chomsky, 1957), as indicated in the clause bracketing in (4).

(4) [the girl (the girl is plump) win ... ]

When listeners encounter the word plump, they have encountered a deep clause boundary, and, on the clausal view, should create a perceptual unit. The two words the plump certainly seem an implausible source of processing overload. Moreover, they seem to comprise a rather "bad" perceptual unit. It would be odd if people really understand sentences by means of such units. (For further similar arguments, see Carroll, Tanenhaus, \& Bever, in press; Carroll \& Tanenhaus, Note 1).

In response to the apparent anomalies regarding examples like (1) through (4), Michael Tanenhaus and I have suggested that purely structural definitions of sentence perception units probably will not be adequate (Carroll \& Tanenhaus, Note 1). Accordingly, we have begun to develop a view of sentence processing units that integrates functional and structural considerations. We conceive of the listener as trying to isolate complete and coherent sets of grammatical relations [e.g., subject-verb-(object); there is some optionality as to the occurrence and number of objects, depending on the verb in question]. We refer to linguistic sequences which provide the listener with an intact subject-verb-(object) group as functionally complete sequences, and we predict that such sequences will be "good" sentence perception units.

We base this conceptualization on current cognitive theories which have emphasized the role of prop- ositional structures as cognitive units (e.g., Fredrickson, 1975; Kintsch, 1974; Rumelhart, Lindsay, \& Norman, 1972). A functionally complete linguistic sequence, as a perceptual unit, projects straightforwardly onto a propositional cognitive unit: A well-formed proposition must include a complete and coherent set of nominal and predicative elements, as a functionally complete sequence must include a complete and coherent set of grammatical relations.

The italicized initial sequences in Sentences 5 through 9 are examples of functionally complete sequences.

(5) John banged the bell to signal the beginning of winter.

(6) That John banged the bell was loudly and painfully obvious.

(7) After John banged the bell he ran off to hide from us.

(8) John who banged the bell swore he would never do it again.

(9) John's banging the bell caused problems for everybody.

In each case, the grammatical relations underlying the sequences are the same: John is the subject noun, bang (in some form) is the verb, and the bell is the object noun. These three grammatical relations comprise a complete and coherent set, and map into a complete and coherent propositional structure. Functionally incomplete sequences fail to do this.

The italicized initial sequences in Sentences 10 through 12 are functionally incomplete.

(10) After banging the bell John was beaten by his sleepy friends.

(11) Banging the bell was possibly the dumbest thing John has yet done.

(12) Since the bell John has not been seen banging anything.

All of these sequences lack an explicit subject relation (i.e., John), and the initial sequence of Sentence 12 lacks both an explicit subject and an explicit verb. ${ }^{1}$

Carroll and Tanenhaus (Note 2, in press) showed that when syntactic variables are held constant, functionally complete clauses and constituents are better processing units than clauses and constituents that are not functionally complete. They used the same click location technique that the original proponents of the clausal and constituent theories employed, 
finding that more clicks were mislocated into boundaries adjacent to functionally complete sequences than into boundaries adjacent to functionally incomplete sequences.

The present experiment attempts to reinforce and extend the investigations of Carroll and Tanenhaus. Besides trying to demonstrate that functional completeness does empirically discriminate between better and poorer sentence perception units, we will try to begin the job of unraveling the mechanism behind this advantage: how are functionally complete sequences recognized? We will consider two possible "cues" to functional completeness: (a) N-V-(N) configurations and (b) inflectional endings on verb stems (for further discussion, see Carroll, 1976; Carroll \& Bever, 1976; and below).

The configuration $\mathrm{N}-\mathrm{V}-(\mathrm{N})$ is an obvious cue to functional completeness. After all, in English, this is the canonical form for complete and coherent sets of grammatical relations: $N-V-(N) \rightarrow$ Subject-Verb(Object). Moreover, there is independent evidence citing the empirical validity of such a cue in language behavior (Bever, 1970). The cue of verb inflection is perhaps less obvious. Note though that, in general, sequences with a tense-bearing verb stem will be functionally complete sequences, while sequences with "deverbal" verb stems (e.g., nominalized verbs) will often be functionally incomplete. None of the functionally incomplete initial sequences in (10) through (12) above contains a tensed verb, while only one of the functionally complete examples (the one in 9) does not contain a tensed verb. ${ }^{2}$ Perhaps it is by recognizing cues like $\mathrm{N}-\mathrm{V}-(\mathrm{N})$ and tense that listeners detect functionally complete sentence perception units.

\section{THE EXPERIMENT}

\section{Method}

The present experiment employs the next-word naming technique of Suci, Ammon, and Gamlin (1967), Suci et al. presented subjects with sentences like (13), followed by probe word excerpts from the sentence.

\section{(13) The small black ant digs holes.}

They measured the time required for subjects to utter the word that had immediately followed the presented word in the original sentence sequence. Thus, if presented with the probe word ant, following Sentence 13, subjects would utter the word digs as quickly as possible.

Suci et al. assume that, other things being equal, next-word naming latencies will be longer to the extent that the probe word and the response word are organized into different perceptual units. ${ }^{3}$ In their study, the longest naming latencies obtained for constituent-final probe words. Thus, in Sentence 13 the longest latencies would be expected for the probe word ant (and the response word digs). That is, when the presented word was the last word in a major constituent (in this case, a sentence-initial noun phrase) and the response word was the first word in the following constituent (in this case, the verb phrase), latencies were longer than for any other probe-word/response-word pairing. Suci et al. conclude from this that the major surface constituents define sentence perception units. (Similar work with probe techniques can be adduced in support of the clausal theory, e.g., Caplan, 1972; for review, see Carroll, 1976.)

The strategy of the present experiment was to hold syntactic properties constant (although this is difficult to do satisfactorily, given the relatively fluid state of syntactic theory; Bach, 1974), and to allow functional completeness (and the occurrence of cues to functional completeness) to vary. If, in this situation, we are still able to measure next-word naming latency differences, the "syntactic" theories of the sentence perception unit can be rejected, just in the sense that the statistical null hypothesis is rejected. ${ }^{4}$

The sentence set in (14) through (17) is typical of experimental materials.

(14) Relative Clause: Howard who revised / the game-rules aggravated the old pros.

(15) Sentential Subject: That Howard revised / the game-rules aggravated the old pros.

(16) Headed Nominalization: Howard's revision of / the gamerules aggravated the old pros.

(17) Headless Nominalization: The revision of / the game-rules aggravated the old pros.

Twenty-four such sentence sets were constructed (see Appendix). The materials were designed to control both syntactic and acoustic properties.

In current formulations of linguistic grammar (Stockwell, Schachter, \& Partee, 1973), the italicized initial sequences in (14) through (17) correspond to both deep structure clauses and major surface constituents. At the deep structure level, these sequences can be glossed as HARRY REVISE THE GAME-RULES. (For details, see Bach, 1974; Vergnaud, 1974; and McCawley, Note 3). At the surface structure level, these initial sequences all correspond to subject noun phrases in the matrix sentence. The claim we make is that in all four sentence types, the juncture between game-rules and aggravated corresponds equally to a deep structure clause boundary and to a major surface constituent boundary. Thus, on either the clausal or the constituent theory, we would predict that all four initial sequence types would serve equally well as units organizing sentence perception.

Acoustic properties were controlled in the following way. First, all 24 sentence sets were recorded on the left channel of a stereo tape recorder in a flatly intoned female voice. Next, the appropriate probe word (e.g., game-rules in the set in 14 through 17), read in a flatly intoned male voice, was spliced in to onset $200 \mathrm{msec}$ after one of the sentences in the set. Which sentence in a given sentence set was selected for this was counterbalanced with respect to sentence types. A trigger tone was manually placed on the right channel of the tape to coincide with the onset of the probe word.

Each set of experimental sentences was then re-recorded. The sentence in each set that had had the probe word spliced after it was copied four times. The final portion of this sentence (e.g., everything after the slash in 14 through 17 ) plus the probe word was then spliced in to replace the corresponding material in the other three sentence versions of the set. Thus, all the members of a given sentence set were acoustically identical from a point before the original occurrence of the probe word in the sentence sequence, through and including the presentation of the probe word $200 \mathrm{msec}$ after the end of the sentence. In the example set, the sequence "the game-rules aggravated the old pros (200-msec delay) gamerules" was identical in all four sentence frames.

Additionally, 24 "distractor" and 6 "warm-up" sentences were prepared. These sentences were grossly comparable to the experimental sentences (e.g., in terms of word length and syntactic 
complexity). As in the case of the experimental sentences, each was read in a female monotone and recorded on the left channel of a stereo tape recorder. The probe words were read in a male monotone, and spliced to onset $200 \mathrm{msec}$ after the sentence. Probe words for distractor sentences were disproportionately chosen from extreme serial positions in the sentence. This was intended to compensate for the fact that the experimental probe words tended to originate in relatively sentence medial positions. Also, distractor sentence probe words were disproportionately articles, verbs, pronouns, adjectives, and prepositions; in sum, they were nonnouns. This was intended to compensate for the fact that the experimental sentence probe words were all nouns.

The distractor and warm-up sentences were then copied four times. Four presentation versions were constructed by combining one copy of the distractor and warm-up sentences with one sentence from each of the 24 experimental sentence sets: In each presentation version, each experimental sentence appeared in a different syntactic form (recall 14 through 17). Presentation versions consisted of six blocks of 8 sentences each: 4 distractor sentences and 4 experimental sentences. Sentence types were counterbalanced by blocks. Sentence type and presentation version were arranged in a Latin square. Thus, for example, if in Presentation Version 2 Sentence 14 appeared in Serial Position 43, then Sentence 15 would appear as Number 43 in Presentation Version 3, etc.

Subjects listened to the presentation versions through headphones. The subject heard only the left channel. After hearing a stimulus sentence and its probe word, the subject was to utter the appropriate following word. The tone on the right channel of the tape coincident with the onset of the probe word triggered a Hunter timer. The subject's vocal response stopped the timer. The elapsed time was the next-word naming latency. On approximately one-quarter of the trials, the subjects were asked to paraphrase the sentence they had just heard. This was intended to encourage them to treat the experimental materials as meaningful sentences, and not just as word lists. Paraphrasing was quite good.

Nineteen subjects participated in the experiment. Three were discarded because they failed to respond with the correct next word on more than a quarter of the trials. Of the remaining 16 , 4 each were assigned to the four presentation versions.

\section{Results and Discussion}

Two sorts of primary results are of interest. First, we want to assess the adequacy of the "syntactic" theories of sentence perception. Since, as we have argued above, neither the clausal nor the constituent theory distinguishes among the four sentence types illustrated in (14) through (17), the predictions of these theories can be assessed by one-way analysis of variance (ANOVA) for the four sentence types (repeated measures design). A significant difference rejects these theories in the sense that the null hypothesis is rejected. However, this is a "negative" result. Of perhaps a more constructive importance is the assessment of the proposed sentence perception cues of $\mathrm{N}-\mathrm{V}-(\mathrm{N})$ configuration and verb inflection. These proposals are evaluated individually by $t$ tests for correlated samples (one-tail predictions). Finally, some ancillary results, qualifications, and further questions are presented.

Table 1 presents summary descriptive statistics. The four sentence types do obtain significant differences overall: by subject, that is, taking subjects as the unit of analysis, with repeated measures on sentence types, $F(3,36)=3.457, p<.05$; by sentence sets, that is, taking sentence sets as the unit of analysis, with repeated measures on sentence types, $F(3,69)=$ $3.151, p<.05$. Less than $6 \%$ of the experimental trials were lost: $3.4 \%$ (13 of 384) of the trials were lost due to equipment malfunction; and $2.3 \%$ (9 of 384) were lost due to errors-subjects uttering an incorrect response word. (Subjects' errors were distributed equally among the four sentence types.) On this basis, then, we reject the unelaborated syntactic theories, and proceed to evaluate the two cues proposed here.

As we have already noted, two of the initial sequence types used in the experimental materials contain verbs with explicit tense morphemes (relative clauses and sentential subjects), ${ }^{5}$ and two contain instead deverbal nominalizations (headed and headless nominalizations). We have argued that sequences with tensed verbal elements ought to be more readily recognized as functionally complete potential sentence perception units. This prediction obtains by subject, $t(15)=3.023, p<.005$, and by sentence set, $\mathrm{t}(23)=2.122, \mathrm{p}<.05$.

Three of the initial sequence types used comprise $\mathrm{N}-\mathrm{V}-(\mathrm{N})$ configurations (relative clauses, sentential subjects, and headed nominalizations), while one sequence type exemplifies an incomplete $\mathrm{V}-(\mathrm{N})$ configuration (headless nominalizations). If the proposed $\mathrm{N}-\mathrm{V}-(\mathrm{N})$ cue is an effective cue identifying functionally complete units to the listener, then N-V(N) sequences ought to obtain longer next-word naming latencies. This prediction also obtains by subject, $\mathrm{t}(15)=2.403, \mathrm{p}<.025$, and by sentence set, $t(23)=2.213, p<.025$. Note that this latter result can also be interpreted simply as showing that functionally complete sequences are better perceptual units than functionally incomplete sequences (Carroll \& Tanenhaus, in press, Note 2).

The foregoing results indicate (a) the inadequacy of syntactic accounts of sentence perception units, and (b) the validity of the proposed N-V-(N) configuration and verb inflection cues. While these are the primary objectives of the present experiment, other questions can of course be raised. Some of these questions can be preliminarily addressed here; others are raised for future investigation. One question involves the independence of the two cues proposed

Table 1

Summary Results: Next-Word Naming Latencies in Milliseconds Overall Means Based On:

\begin{tabular}{lcc}
${ } }$ & $\begin{array}{c}\text { By-Subject } \\
\text { Geometric } \\
\text { Means }\end{array}$ & $\begin{array}{c}\text { By-Item } \\
\text { Geometric } \\
\text { Means }\end{array}$ \\
\hline Sentential Subject & 1559 & 1570 \\
Headed Nominalization & 1438 & 1465 \\
Headless Nominalization & 1394 & 1412 \\
\hline
\end{tabular}


here. Both cues are partially confounded with each other in the analysis presented above. In a sense, this is not problematic, since the two cues are ecologically correlated to a great extent. However, from the perspective of a (presently nonexistent) more complete information processing analysis of sentence perception cues, it may be of interest to assess the separate contribution of each cue to the final determination of a sentence perception unit.

Both tensed verb sequence types (relative clauses and sentential subjects) comprise $\mathrm{N}-\mathrm{V}-(\mathrm{N})$ configurations, yet only one nominalization type does this (headed but not headless). Thus, in order to assess verb inflection without $\mathrm{N}-\mathrm{V}-(\mathrm{N})$, the two tensed verb sequence types should be contrasted only with headed nominalizations. The remaining difference is significant by subject, $\mathrm{t}(15)=2.327, \mathrm{p}<.025$, and nearly so by sentence set, $t(23)=1.479, p=.077 .{ }^{6}$ In order to assess the N-V-(N) cue without verb inflection, headed nominalizations [complete $\mathrm{N}-\mathrm{V}-(\mathrm{N})$ ] were contrasted with headless nominalizations [incomplete $\mathrm{V}-(\mathrm{N})$ ]. This difference reduces to a nonsignificant trend $(\mathrm{p}=.19$, by subject; $\mathrm{p}=.13$, by sentence set). ${ }^{7}$

Another question regards elaborating the verb inflection cue. There are two major classes of nominalizations in English: substantive (as illustrated in 16 and 17) and gerundive, or "-ing." Each type appeared, counterbalanced and with equal frequency, in all of the presentation versions of the present experiment. Substantive nominalizations have a variety of inflectional forms: refusal, criticism, construction, amusement, etc. However, gerundive nominalizations have only one inflectional form: refusing, criticising, constructing, amusing, etc.

There are extensive discussions of the linguistic differences between these nominalization types (e.g., Jackendoff, Note 4). However, for present purposes, consider the differences between them as potential sentence perception cues. Both classes of nominalization inflections denote the same property vis-à-vis functional completeness, namely the possibility of functional incompleteness. However, both also identify a semantically verbal element in a linguistic sequence, and therefore can also serve to inform the listener that at least one prerequisite for functional completeness has been satisfied. The basic difference between gerundive and substantive nominalizations, then, is that the inflectional morpheme is stereo-

Table 2

Summary Results for Nominalizations:

Means of By-Subject Geometric Means

\begin{tabular}{lcc}
\hline Nominalization Type & Gerundive & Substantive \\
\hline Headed Nominalizations & 1448 & 1397 \\
Headless Nominalizations & 1352 & 1278 \\
All Nominalizations & 1422 & 1314 \\
\hline
\end{tabular}

typical in the former class ("-ing"), but quite varied in the latter. As a cue, the gerundive morpheme might be easier to recognize, and therefore, perhaps, easier to make use of in perceiving sentences.

A separate analysis of variance was conducted for the nominalization sentences. The ANOVA had the two crossed factors of Nominalization Type (substantive vs. gerundive) and Configuration [N-V-(N) headed vs. V-(N) headless], and was computed both by subject and by sentence set. However, a significant effect of Nominalization Type obtains only by subject, $\mathrm{p}<.005[\mathrm{~F}(1,12)=12.73]$. Refer to Table 2 for summary statistics. Accordingly, there is some reason to believe that gerundive nominalizations cue the listener to create a perceptual unit to a greater extent than do substantive nominalizations. However, the fact that this result is nonsignificant by sentence set means that we cannot generalize the finding beyond the particular set of nominalizations used in the experimental materials.

A third question concerns the role of other possible cues in sentence perception. The N-V-(N) and verb inflection cues denote the property of functional completeness, but clearly other factors might contribute to the determination of the units listeners use in perceiving speech. One such factor might be "sequence length": lengthy sequences may provide added impetus to create a perceptual unit by overtaxing processing capacities. The correlation between mean next-word naming latency and length in words of the initial sequence for the 96 experimental sentences is $\mathrm{r}=+.465, \mathrm{p}<.001$. This correlation persists when the set of items in each sequence type is examined separately: for relative clauses, $r=+.51$, $\mathrm{p}<.01$; for sentential subjects, $\mathrm{r}=+.56, \mathrm{p}<.005$; for headed nominalizations, $\mathrm{r}=+.35$, $\mathrm{p}<.05$; and for headless nominalizations, $r=+.26$, n.s. These results suggest that the "cue" of sequence length does indeed enter into the determination of sentence perception units. (Note also that "sequence length" is not a syntactic property, so this result further impugns the syntactic approach criticized earlier; see Tanenhaus \& Carroll, Note 5, for a direct experimental study of the sequence length cue.)

It is likely that many other cues are involved as well. Extrasentential context might be one. Context can provide the listener with information about the identity of key grammatical relations in a discourse. For example, in ordinary conversational contexts, the deleted subject relation in a headless nominalization construction (e.g., 17 above) would often be provided to the listener via preceding discourse (or ostensive) context. Tanenhaus (1978) presents several experimental results which encourage this view.

\section{GENERAL DISCUSSION}

From the viewpoint of the present investigation, it 
should never have been expected that listeners would mechanistically treat proper syntactic units, be they clauses or constituents, as sentence perception units. Listeners are not linguists, and while they obviously want to recover something akin to the logical structure of sentences they hear, they can, unlike linguists, afford a considerable amount of flexibility in this. It is not always necessary to perceptually construct a complete syntactic derivation; it will often suffice to capture merely the gist, and possibly less. Perhaps more importantly though, it seems that listeners cannot afford to be inflexible. The limitations inherent to human information processing demand that the listener employ heuristics to short-cut complex tasks like sentence perception. Not only can listeners afford flexibilities linguists cannot, they rely on such flexibilities.

The present experiment demonstrates the empirical validity of this line of thinking. In a critical contrast, for which syntactic theories of sentence perception units predict no differences, significant differences obtain. ${ }^{8}$ Moreover, heuristically motivated perceptual cues $d o$ appear to structure the determination of sentence perception units, and to predict the obtained latency differences. Thus, the syntactic theories are refuted (cf. footnote 4), and the alternative functional program is elaborated.

\section{APPENDIX}

\section{Warm-up Sentences}

Sentences i to vi were practice sentences. Immediately following each sentence, the capitalized probe word appears.

(i) In less than thirty minutes this jet plane could be in Bagdad. COULD

(ii) Penny lost the first five games but her determination to win helped her win the next six and later the tournament championship. GAMES

(iii) Only Saigon remained in the hands of South Vietnamese government after the terrible onslaught of the Viet Cong. ONSLAUGHT

(iv) The local School Board elections will be held next Tuesday but the outcome is already certain. TUESDAY

(v) John has been gone since morning. JOHN

(vi) Chasing his dog under the table is one of Roger's odd habits. ONE

\section{Distractor Sentences}

The numbers preceding each sentence refer to the sentence's position in the presentation sequence.

(1) Hiding my friend's hat the small girl laughed at his strange predicament. FRIENDS

(5) John ran quite fast but we caught him in the narrow alley. NARROW

(6) When he stood up my son's book fell from the low table. STOOD

(8) After a few tries the boy beat his father at chinese checkers. AT

(12) The boy and girl won and lost at cards during the afternoon. BOY
(13) They fought tooth and nail to get past the huge angry crowd. AND

(14) By making his plan known Jim brought out the objections of everybody. OBJECTIONS

(16) In order to see out the small child pushed up the window. SMALL

(17) To determine the tree's age those boys asked the old forest ranger. THOSE

(18) In addition to his wives the prince brought the court's only dwarf. ONLY

(21) The inexperienced pilot lost his breath since the plane dove too fast. BREATH

(22) If you did call up Bill I thank you for your trouble. BILL

(28) The guard took your Aunt's purse in which she had ten dollars. TOOK

(29) They asked the mean old man to be kind to his dog. KIND

(31) Since she was free that day her friends asked her to come. SINCE

(32) When the new minister called up Fred the plan was discussed thoroughly. WAS.

(33) Any student who is bright but young would not have seen it. WOULD

(36) That the matter was dealt with fast was a shock to Harry. SHOCK

(37) After the dry summer of that year most crops were completely lost. DRY

(39) That a solution could not be found seemed quite clear to us. COULD

(43) The boy who was waiting in the hall was a new student. WHO

(45) The lawyer who couldn't decide what to do sat down in disgust. DECIDE

(47) Not quite all of the brand new chairs were shipped that day. SHIPPED

(48) The entire skiing party feeling nice and warm laughed and sang loudly. LAUGHED

\section{Experimental Sentences}

Numbers preceding experimental sentence sets refer to the order of their presentation. Roman numerals preceding sentence types within a sentence set refer to the presentation version (I, II, III, or IV) that exemplar appeared in. Cross-splicing points (i.e., the point after which all sentences belonging to the same set were acoustically identical) are indicated by a slash. All sentence sets are arranged in this order: relative clause version; sentential subject version; headed nominalization version; headless nominalization version.

(2) (III) The children who left / for school too late on Monday caused problems for the teacher. MONDAY

(II) That the children left / for school too late on Monday caused problems for the teacher. MONDAY

(IV) The children's leaving / for school too late on Monday caused problems for the teacher. MONDAY

(l) Leaving / for school too late on Monday caused problems for the teacher. MONDAY

(3) (I) The women who insisted / on the right to free speech won many new converts. SPEECH 
(IV) That the women insisted / on the right to free speech won many new converts. SPEECH

(II) The women's insisting / on the right to free speech won many new converts. SPEECH

(III) Insisting / on the right to free speech won many new converts. SPEECH

(4) (IV) John who believes / in the corporate system angers the radicals. SYSTEM

(III) That John believes / in the corporate system angers the radicals. SYSTEM

(I) John's belief / in the corporate system angers the radicals. SYSTEM

(II) The belief / in the corporate system angers the radicals. SYSTEM

(7) (II) The reporter who is curious / about the new program has become a problem. PROGRAM

(I) That the reporter is curious / about the new program has become a problem. PROGRAM

(III) The reporter's curiosity / about the new program has become a problem. PROGRAM

(IV) The curiosity / about the new program has become a problem. PROGRAM

(9) (II) The children who ran / home from school worried the parents. SCHOOL

(I) That the children ran / home from school worried the parents. SCHOOL

(III) The children's running / home from school worried the parents. SCHOOL

(IV) Running / home from school worried the parents. SCHOOL

(10) (IV) The men who voted / for a strike incensed the company president. STRIKE

(III) That the men voted / for a strike incensed the company president. STRIKE

(I) The men's voting / for a strike incensed the company president. STRIKE

(II) The voting / for a strike incensed the company president. STRIKE

(11) (I) The lawyer who resigned / from city council surprised everyone. COUNCIL

(IV) That the lawyer resigned / from city council surprised everyone. COUNCIL

(II) The lawyer's resignation / from city council surprised everyone. COUNCIL

(III) The resignation / from city council surprised everyone. COUNCIL

(15) (III) Mary who argued / with the playground bully spoiled the party. BULLY

(II) That Mary argued / with the playground bully spoiled the party. BULLY

(IV) Mary's argument / with the playground bully spoiled the party. BULLY

(I) The argument / with the playground bully spoiled the party. BULLY

(19) (IV) The women who ganged / up on the young and incompetent secretary caused tension at the office. SECRETARY

(III) That the women ganged / up on the young and incompetent secretary caused tension at the office. SECRETARY

(I) The women's ganging / up on the young and incompetent secretary caused tension at the office. SECRETARY

(II) Ganging / up on the young and incompetent secretary caused tension at the office. SECRETARY

(20) (III) The committee that considered / the lay-off alarmed many of the workers. LAY-OFF

(II) That the committee considered / the lay-off alarmed many of the workers. LAY-OFF

(IV) The committee's consideration of / the lay-off alarmed many of the workers. LAY-OFF

(I) The consideration of / the lay-off alarmed many of the workers. LAY-OFF

(23) (I) Susan who disagreed / about the little children caused a lot of excitement. CHILDREN

(IV) That Susan disagreed / about the little children caused a lot of excitement. CHILDREN

(II) Susan's disagreement / about the little children caused a lot of excitement. CHILDREN

(III) The disagreement / about the little children caused a lot of excitement. CHILDREN

(24) (II) The men who punished / the small boy's greediness seemed cruel. GREEDINESS

(I) That the men punished / the small boy's greediness seemed cruel. GREEDINESS

(III) The men's punishing / the small boy's greediness seemed cruel. GREEDINESS

(IV) Punishing / the small boy's greediness seemed cruel. GREEDINESS

(25) (I) The children who misbehaved / at the movie upset the ushers. MOVIE

(IV) That the children misbehaved / at the movie upset the ushers. MOVIE

(II) The children's misbehaving / at the movie upset the ushers. MOVIE

(III) The misbehaving / at the movie upset the ushers. MOVIE

(26) (III) The children who laughed / in church enraged the preacher. CHURCH

(II) That the children laughed / in church enraged the preacher. CHURCH

(IV) The children's laughing / in church enraged the preacher. CHURCH

(I) The laughing / in church enraged the preacher. CHURCH

(27) (IV) The team which was amused / at John's foolishness embarrassed him. FOOLISHNESS

(III) That the team was amused / at John's foolishness embarrassed him. FOOLISHNESS

(I) The team's amusement / at John's foolishness embarrassed him. FOOLISHNESS

(II) The amusement / at John's foolishness embarrassed him. FOOLISHNESS

(30) (II) The army which destroyed / the city frightened people. CITY 
(I) That the army destroyed / the city frightened people. CITY

(III) The army's destruction of / the city frightened people. CITY

(IV) The destruction of / the city frightened people. CITY

(34) (I) The men who misunderstood / the meaning of the signal caused a lot of confusion. SIGNAL

(IV) That the men misunderstood / the meaning of the signal caused a lot of confusion. SIGNAL

(II) The men's misunderstanding / the meaning of the signal caused a lot of confusion. SIGNAL

(III) Misunderstanding / the meaning of the signal caused a lot of confusion. SIGNAL

(35) (II) The old lady who refused / to accept criticism led people to regard her as haughty. CRITICISM

(I) That the old lady refused / to accept criticism led people to regard her as haughty. CRITICISM

(III) The old lady's refusal / to accept criticism led people to regard her as haughty. CRITICISM

(IV) The refusal / to accept criticism led people to regard her as haughty. CRITICISM

(38) (IV) The professor who criticized / the book was selfserving. BOOK

(III) That the professor criticized / the book was self-serving. BOOK

(I) The professor's criticism of / the book was selfserving. BOOK

(II) The criticism of / the book was self-serving. BOOK

(40) (III) The men who demanded / a large raise initiated new policies. RAISE

(II) That the men demanded / a large raise initiated new policies. RAISE

(IV) The men's demanding / a large raise initiated new policies. RAISE

(I) Demanding / a large raise initiated new policies. RAISE

(41) (III) Nancy who proved / the difficult theorem was applauded widely. THEOREM

(II) That Nancy proved / the difficult theorem was applauded widely. THEOREM

(IV) Nancy's proof of / the difficult theorem was applauded widely. THEOREM

(I) The proof of / the difficult theorem was applauded widely. THEOREM

(42) (II) The women who allowed / Mary to resign from of fice disappointed the club's members. OFFICE

(I) That the women allowed / Mary to resign from office disappointed the club's members. OFFICE

(III) The women's allowing / Mary to resign from of fice disappointed the club's members. OFFICE

(IV) Allowing / Mary to resign from office disappointed the club's members. OFFICE

(44) (IV) The women who yelled / at the rally distracted the delegates, RALLY
(III) That the women yelled / at the rally distracted the delegates. RALLY

(I) The women's yelling / at the rally distracted the delegates. RALLY

(II) The yelling / at the rally distracted the delegates. RALLY

(46) (I) Howard who revised / the game-rules aggravated the old pros. GAME-RULES

(IV) That Howard revised / the game-rules aggravated the old pros. GAME-RULES

(II) Howard's revision of / the game-rules aggravated the old pros. GAME-RULES

(III) The revision of / the game-rules aggravated the old pros. GAME-RULES

\section{REFERENCE NOTES}

1. Carroll, J., \& Tanenhaus, M. Sentence perception: The interaction of structural functional, and contextual factors. Manuscript in preparation.

2. Carroll, J., \& Tanenhaus, M. Functional clauses are the primary units of sentence segmentation. Indiana University Linguistics Club Mimeo, 1975.

3. McCawley, J. A review of Noam A. Chomsky's Studies on semantics in generative grammar. Indiana University Linguistics Club Mimeo, 1973.

4. Jackendoff, R. Introduction to the "X-Bar" convention. Indiana University Linguistics Club Mimeo, 1974.

5. Tanenhaus, M., \& Carroll, J. Sequence length as a sentence segmentation cue. Manuscript in preparation.

\section{REFERENCES}

BACr, E. Syntactic theory. New York: Holt, 1974.

BEVER, $T$. The cognitive basis for linguistic structures. In J. Hayes (Ed.), Cognition and the development of language. New York: Wiley, 1970.

BeVER, T., LACKNER, J., \& KIRK, R. The underlying structures of sentences are the primary units of immediate speech processing. Perception \& Psychophysics, 1969, 5, 225-231.

CAPLAN, D. Clause boundaries and recognition latencies for words in sentences. Penception \& Psychophysics, 1972, 12, 73-76.

CARRolL, J. The interaction of structural and functional variables in sentence perception: Some preliminary studies. Doctoral dissertation, Columbia University, 1976.

Carroll, J., \& Bever, T. Sentence comprehension: A case study in the relation of knowledge to perception. In $E$. Carterette \& M. Friedman (Eds.), The handbook of perception (Vol. 7) Speech and language. New York: Academic Press, 1976.

Carroll, J., \& Tanenhaus, M. Functional clauses and sentence segmentation. Journal of Speech and Hearing Research, 1978, in press.

Carroll, J., Tanenhaus, M., \& Bever, T. The perception of relations: The interaction of structural, functional, and contextual factors in the segmentation of sentences. In W. Levelt \& G. Flores d'Arcais (Eds.), Studies in the perception of language. New York: Wiley, 1978, in press.

Chapin, P., Smith, T., \& Abrahamson, A. Two factors in perceptual segmentation of speech. Journal of Verbal Learning and Verbal Behavior, 1972, 11, 164-173.

Сномsкy, N. Syntactic structures. The Hague: Mouton, 1957.

CномsкY, N. Remarks on nominalizations. In R. Jacobs \& P. Rosenbaum (Eds.), Readings in English transformation grammar. Waltham, Mass: Ginn, 1970.

FODOR, J., \& BEVER, T. The psychological reality of linguistic 
segments. Joumal of Verbal Learning and Verbal Behavior, $1965,4,414-420$.

Fodor, J., BeVER, T., \& GARRETT, M. The psychology of language. New York: McGraw-Hill, 1974.

Frederickson, C. Effects of context-induced processing operations on semantic information acquired from discourse. Cognitive Psychology, 1975, 7, 139-166.

Kemper, S., Catlin, J., \& Bowers, J. On the surface structure of infinitive-complement sentences. Journal of Psycholinguistic Research, 1977, 6, 1-19.

MilleR, G. The magical number seven plus or minus two: Some limits on our capacity for processing information. Psychological Review, 1956, 63, 81-96.

Rumelhart, D., Lindsay, P., \& Norman, D. A process model for long-term memory. In E. Tulving \& W. Donaldson (Eds.), Organization of memory. New York: Academic Press, 1972.

Slobis, D. Cognitive prerequisites for the development of grammar. In C. Ferguson \& D. Slobin (Eds.), Studies of child language development. New York: Holt, 1971.

Stockwell, R., Schachter, P., \& Partee, B. The major syntactic structures of English. New York: Holt, Rinehart, \& Winston, 1973.

Suci, G., Ammon, P., \& Gamlin, P. The validity of the probe-latency technique for assessing structure in language. Language and Speech, 1967, 10, 69-80.

Tanenhaus, M. Linguistic context and sentence perception. Doctoral dissertation, Columbia University, 1978.

Vergnaud, J. French relative clauses. Doctoral dissertation, M.I.T., 1974

\section{NOTES}

1. The functionally incomplete sequences dealt with in the present study fail to provide an explicit intact subject-verb-(object) group to the listener. It is also possible to contrive examples which fail to be functionally complete because the intact subjectverb-(object) sequence is incoherent, as illustrated by (i) and (ii).

(i) John's drinking partner made a total ass of him.

(ii) John's drinking beer made a total ass of him.

The italicized nominalization in (ii) provides a coherent N-V-(N) sequence, and a functionally complete unit. The corresponding sequence in (i) provides a potential N-V-(N) sequence, but if interpreted thusly, Sentence i is incoherent. Accordingly, the italicized sequerce in (i) is functionally incomplete.

2. Slobin (1971) argues that inflectional endings are cues with which the young child discovers the grammer of his language. Carroll (1976, pp. 207-213) considers the relation between this acquisition mechanism and the perceptual mechanism proposed here.

3. The Suci et al. task consists of a memory probe. While the probe delay is relatively brief, this technique obviously does not allow any direct insight into the actual "on-line" processes that structure perception. The use of the word "perceptual" in the present discussion must be understood accordingly.

4. And, of course, with the same qualifications. The issue of the syntactic analysis of the materials used in the experiment is critical. It is argued below that all of the four sentence types studied have identical gross syntactic analyses at both the (deep) clausal and (surface) constituent levels. One can reject this claim in principle, arguing that the indeterminate state of linguistics prohibits such a test, but only at the cost of rendering the entire matter nonempirical. The viewpoint adopted here is that it is better to make the test, keeping in mind that theories sometimes change, and empirical results may accordingly demand new interpretations.

5. "Explicit tense" indicates that there is some actual acoustic reflex of the tense morpheme. The verb walk in (i) is third person present tensed, while in (ii) it is a nominalization.

(i) They walk up the hill ...

(ii) The walk up the hill...

Note, though, that the instances of walk would not be acoustically differentiated. This doesn't necessarily mean that tense cannot be a cue in (i), but it makes the possible mechanism rather obscure, In the present experiment, explicit tense morphemes occurred in all tensed versions, for example:

(iii) The men who walked up the hill ...

6. Somewhat ironically, when a $t$ test for uncorrelated samples is performed, this difference becomes significant, $\mathrm{p}<.025$, $t=2.152$, df $=70$. (This latter test compares relative clause and sentential subject sentence types, $n=48$; with headed nominalization sentence types, $n=24$.) Although our item analyses have correlated samples overall, each subject contributes data to only one sentence-type version from each of the 24 sentence sets. Hence, when subject variance is greater than item variance, correlated samples tests may be less powerful than tests for uncorrelated samples. (I am grateful to M. K. Tanenhaus for calling this to my attention.)

7. Carroll, Tanenhaus, and Bever (in press) suggest that the verb tense cue "costs" the listener less, in terms of processing, than the $\mathrm{N}-\mathrm{V}-(\mathrm{N})$ cue. The latter cue involves recognizing a "configuration" of potential grammatical relations, while the former, to a great extent, is a "local sign."

8. The converse of the present experiment would also represent a critical contrast: hold functional completeness of experimental sequences constant, and allow only syntactic properties to vary. A strong extension of the viewpoint developed here would predict no difference in such a contrast. Thus, as the present experiment offers a way of rejecting the "syntactic" theories, its converse offers a way of rejecting the functional completeness "theory."

(Received for publication January 31, 1978; accepted March 16, 1978.) 